\title{
ANALISIS PENGELOLAAN ANGGARAN PENDAPATAN DAN BELANJA DESA (APBDesa) DI DESA TANJUNG RAJA KECAMATAN STM HULU KABUPATEN DELI SERDANG
}

\author{
${ }^{1}$ Tio Fanta Purba, ${ }^{2}$ Mas'ut \\ ${ }^{1,2}$ Universitas Islam Sumatera Utara \\ ${ }^{1}$ tiofantapurba83351@gmail.com, ${ }^{2}$ m.masut@yahoo.com,
}

\begin{abstract}
This study aims to see the implementation of APBDes and village openness to the people of Tanjung Raja Village, STM Hulu district, Deli Serdang Regency during the 2017-2018 period. The type of research used in this research in qualitative research, while the research method used is descriptive method. The data collection tecniques carried out were by observing the field (Tanjung Raja Village Head, Treasurer, village officials and also the Tanjung Raja Village community. In addition, the documentation technique is to collect data related to APBDes and other influential documents. The sample in this study was in one sample, namely Tanjung Raja village, STM Hulu District, Deli Serdang Regency. This research proves that the preparation of APBDes in Tanjung Raja village is in accordance with the rules set by government. However, there are still things that need to be improved, such as the absence of Bumdes in Tanjung Raja village.
\end{abstract}

Keywoards : Transparency, Accountability, APBDes

ABSTRAK : Penelitian ini bertujuan untuk melihat penerapan APBDes dan keterbukaan desa kepada masyarakat Desa Tanjung Raja Kecamatan STM Hulu Kabupaten Deli Serdang selama periode 2017-2018. Jenis penelitian yang digunakan dalam penelitian ini adalah penelitian kualitatif, sedangkan metode penelitian yang digunakan adalah metode deskriptif. Adapun teknik pengumpulan data yang dilakukan adalah dengan melakukan observasi ke lapanang (Kantor Desa Tanjung Raja dan perkampungan), juga melakukan wawancara kepada Kepala Desa Tanjung Raja, Bendahara, perangkat desa dan juga masyarakat Desa Tanjung Raja. Selain itu teknik dokumentasi yaitu dengan memgumpulkan data-data yang bersangkutan dengan APBDes dan dokumen berpengaruh lainnya. Sampel dalam penelitian ini terdapat pada satu sampel yaitu Desa Tanjung Raja Kecamatan STM Hulu Kabupaten Deli Serdang. Dari penelitian ini membuktikan bahwa penyusunan APBDes pada Desa Tanjung Raja sudah sesuai dengan aturan yang telah ditetapkan oleh pemerintah. Namun masih ada yang perlu disempurnakan seperti tidak adanya BumDes pada desa Tanjung Raja.

Kata Kunci : Transparansi, Akuntabilitas, APBDes.

\section{Pendahuluan}

\subsection{Latar Belakang Masalah}

Indonesia sebagai suatu negara yang dibangun diatas dan dari desa, desa merupakan pelopor sistem demokrasi yang otonom dan berdaulat penuh.

Sejak lama, desa telah memiliki sistem mekanisme pemerintahan serta norma sosial masing-masing. Inilah cikal bakal sebuah negara bernama Indonesia ini. Istilah desa sering kali identic dengan masyarakat yang miskin, tradisionalis dan kolot. Namun sebenarnya desa mempunyai keluhuran dan kearifan lokal yang luar biasa. Desa adalah pelopor sistem demokrasi yang otonom dan berdaulat penuh sejak lama, desa telah memiliki sistem dan mekanisme pemerintahan serta norma sosial masing-masing.

Berdasarkan Undang-undang Nomor 6 Tahun 2014 tentang desa, yang dimaksud dengan desa adalah kesatuan masyarakat hukum yang memiliki batas wilayah yang berwenang untuk mengatur dan mengurus urusan pemerintahan, kepentingan masyarakat setempat berdasarkan prakarsa masyarakat, hak asal usul, atau salah satu aspek yang ikut 
berperan dalam pengembangan desa adalah keuangan desa dan aset desa. keuangan desa berkaitan dengan hak dan kewajiban desa yang dapat dinilai dengan uang, sedangkan aset desa adalah barang milik desa yang berasal dari kekayaan asli desa, dibeli atau diperoleh atas beban anggaran pendapatan dan belanja desa atau perolehan hak lainnya yang sah.

Sebagaimana yang sudah ditetapkan dalam Undang-undang Nomor 6 Tahhun 2014 tentang desa, yakni penatausahaan keuangan pemerintah desa terpisah dari keuangan pemerintah Kabupaten. Desa telah menjadi kesatuan masyarakat hukum yang memiliki batas wilayah yang berwenang untuk mengatur dan mengurus kepentingan masyarakat setempat beserta urusan pemerintahan berdasarkan prakarsa, asal-usul dan adat istiadat masyarakat setempat serta hak tradisional yang diakui dan dihormati dalam sistem pemerintahan Negara Kesatuan Republik Indonesia (NKRI).

Pemerintah desa merupakan bagian dari birokrasi negara dan sekaligus sebagai pimpinan lokal yang memiliki posisi dan peran yang signifikan dalam membangun dan mengelola pemerintahan desa. Tugas utama yang harus diemban pemerintah desa yaitu menciptakan kehidupan masyarakat yang demokratis, dan mendorong pemeberdayaan masyarakat serta memberikan pelayanan publik yang baik (Dipayana, 2003:15).

Berdasarkan Peraturan Menteri Dalam Negeri No 20 Tahun 2018 pengelolaan keuangan desa merupakan seluruh kegiatan yang meliputi perencanaan, pelaksanaan, penatausahaan, pelaporan dan pertanggungjawaban keuangan desa. Adapun asas pengelolaan keuangan desa berdasarkan Permendagri 20 Tahun 2018 yaitu :

1). Keuangan desa dikelola berdasarkan asas transparan, akuntabel, partisipatif serta dilakukan dengan tertib dan disiplin anggaran.

a. Yang dimaksud Transparan yaitu prinsip keterbukaan yang memungkinkan masyarakat untuk mengetahui dan mendapat akses informasi seluas-luasnya tentang keuangan desa.

b. Akuntabel yaitu perwujudan kewajiban untuk mempertanggungjawabkan pengelolaan dan pengendalian sumber daya dan pelaksanaan kebijakan yang dipercayakan dalam rangka pencapaian tujuan yang telah ditetapkan. c. Partisipatif yaitu penyelenggaraan pemerintah desa yang mengikutsertakan kelembagaan dan unsur masyarakat desa.

d. Tertib dan disiplin anggaran yaitu pengelolaan keuangan desa harus mengacu pada aturan atau pedoman yang melandasinya.

2). Anggaran Pendapatan dan Belanja Desa merupakan dasar pengelolaan keuangan desa dalam masa satu tahun anggaran mulai 1 Januari sampai dengan tanggal 31 Desember.

Berdasarkan Peraturan Menteri Dalam Negeri 20 Tahun 2018 Anggaran Pendapatan dan Belanja Desa (APBDes) merupakan rencana keuangan tahunan pemerintahan Desa. Menurut Mardiasmo, (2009:61) Anggaran merupakan pernyataan mengenai estimasi kinerja yang ingin dicapai selama periode waktu tertentu yang dinyatakan dalam ukuran finansial. Dalam Permendagri 20 Tahun 2018 Anggaran Pendapatan dan Belanja Desa (APBDes) terdiri dari; Pendapatan Desa, belanja Desa, dan pembiayaan Desa.

Berdasarkan Peraturan Menteri Dalam Negeri No 20 tahun 2018 pendapatan merupakan semua penerimaan desa dalam satu tahun anggaran yang menjadi hak desa dan tidak perlu dikembalikan oleh desa. Pendapatan terdiri atas

a. Pendapatan asli desa

Yang termasuk dalam pendapatan asli desa yaitu: hasil usaha, hasil aset, swadaya, partisipasi, gotong royong, dan pendapatan asli desa lain.

b. Transfer

Pendapatan transfer terdiri dari dana desa, bagi hasil pajak daerah kabupaten/kota, alokasi dana desa, bantuan keuangan dari Anggaran Pendapatan Belanja Daerah Provinsi, bantuan keuangan dari Anggaran Pendapatan Belanja Daerah Provinsi dan Daerah.

c. Pedapatan Lain

Pendapatan lain yang dimaksud yaitu: penerimaan dari hasil kerja sama desa, penerimaan dari bingtuan perusahaan yang berlokasi di desa, penerimaan hibah dan sumbangan dari pihak ketiga, koreksi kesalahan belanja tahun anggaran sebelumnya yang mengakibatkan penerimaan dikas desa pada tahun anggaran berjalan, bunga bank, dan pendapatan lain desa yang sah. 
Peran pemerintah desa sangat diharapkan dalam memanfaatkan hasil potensi desa melalui APBDes , karena APBDes merupakan instrumen yang sangat penting dalam mewujudkan pemerintahan yang baik di tingkat desa. Dengan kata lain tata pemerintahan yang baik diukur dari bagaimana pemerintah desa bekerja secara mandiri dalam mengelolan potensi-potensi yang ada didesa, sehingga pengelolaan APBDes yang disusun benar-benar berorientasi kepada peningkatan kesejahteraan masyarakat desa.

Tabel 1.Laporan APBDes Tahun 2017 Desa Tanjung Raja

\begin{tabular}{|l|l|r|r|}
\hline Kode Rek & Uraian & Anggaran (Rp) & Ket \\
\hline 1. & Pendapatan & $1.117 .899 .000,00$ & \\
\hline 1.1 & Pendapatan Asli Desa (PAD) & 0,00 & \\
\hline 1.2 & Pendapatan Transfer & $1.117 .899 .000,00$ & \\
\hline 1.2 .1 & Dana Desa & $772.891 .000,00$ & \\
\hline 1.2 .2 & Dana Hasil Pajak dan Retribusi Daerah & $51.426 .000,00$ & \\
\hline 1.2 .3 & Alokasi Dana Desa & $293.582 .000,00$ & \\
\hline 1.3 & Pendapatan Lain-lain & 0,00 & \\
\hline & Jumlah Pendapatan & $1.117 .899 .000,00$ & \\
\hline
\end{tabular}

Sumber : Data Laporan APBDes

Tabel 2. Laporan APBDes Tahun 2018 Desa Tanjung Raja

\begin{tabular}{|l|l|r|r|}
\hline Kode Rek & Uraian & Anggaran (Rp) & Ket \\
\hline 1 & Pendapatan & $1.079 .662 .000,00$ & \\
\hline 1.1 & Pendapatan Asli Desa (PAD) & $172.000,00$ & \\
\hline 1.2 & Pendapatan Transfer & $1.079 .490 .000,00$ & \\
\hline 1.2 .1 & Dana Desa & $679.520 .000,00$ & \\
\hline 1.2 .2 & Dana Hasil Pajak dan Retribusi Daerah & $51.852 .000,00$ & \\
\hline 1.2 .3 & Alokasi Dana Desa & $348.118 .000,00$ & \\
\hline 1.3 & Pendapatan Lain-lain & 0,00 & \\
\hline & Jumlah Pendapatan & $1.079 .662 .000,00$ & \\
\hline
\end{tabular}

Sumber : Data Laporan APBDes

Dari penjelasan tabel diatas, ditemukan permasalahan yang muncul. Yang dimana pengelolaan Anggaran Pendapatan dan Belanja Desa di Desa Tanjung Raja Kecamatan STM Hulu belum berjalan dengan baik. Hal ini dikarenakan pada tahun 2017 tidak terdapat adanya Pendapatan Asli Desa (PAD) dan pada tahun 2018 Pendapatan Asli Desa (PAD) hanya sebesar 172.000. Hal ini disebabkan karena tidak adanya hasil usaha (BUMDes), hasil aset, patrisipasi dan gotong royong.

Oleh karena itu peneliti memiliki ketertarikan untuk meneliti tentang APBdes, dikarenakan APBDes memiliki implikasi yang besar dalam pembangunan sebuah desa. Faktor lain yang mendorong penulis untuk melakukan penelitian pengelolaan APBDes di Desa Tanjung Raja Kecamatan STM HULU, karena peneliti ingin menjelaskan sistem transparansi dan akuntabilitas perencanaan, pelaksanaan, pelaporan, pertanggungjawaban dari pengelolaan APBDes di Desa Tanjung Raja. Peneliti memilih meneliti program ini karena jika dana kelola secara jujur dan baik, maka hasilnya pembangunan juga terlihat dengan jelas. Sehubung dengan uraian diatas, maka penulis tertarik mengadakan penelitian dengan judul "Analisis Pengelolaan Anggaran Pendapatan dan Belanja Desa (APBDes).

\subsection{Rumusan Masalah}

Berdasarkan uraian latar belakang diatas, maka peneliti dapat membuat rumusan masalah yang terjadi di Desa Tanjung Raja, Kecamatan STM Hulu Kabupaten Deli Serdang sebagai berikut :

a. Apakah pengelolaan Anggaran Pendapatan dan Belanja Desa (APBDes) di Desa Tanjung Raja Kecamatan STM Hulu Kabupaten Deli Serdang Tahun 2017 dan Tahun 2018 sudah sesuai dengan Undangundang No 6 Tahun 2014?

b. Bagaimanakah akuntabilitas pemerintah desa dalam pengelolaan Anggaran Pendapatan dan Belanja Desa (APBDes) di Desa Tanjung Raja Kecamatan STM Hulu 
Kabupaten Deli Serdang Tahun 2017 dan Tahun 2018?

c. Bagaimana transaparansi pengelolaan Anggaran Pendapatan dan Belanja Desa (APBDes) di Desa Tanjung Raja Kecamatan STM Hulu Kabupaten Deli Serdang Tahun 2017 dan Tahun 2018?

\subsection{Tujuan Penelitian}

Berdasarkan pokok permasalahan yang sudah dipaparkan diatas, tujuan dari peneliatian ini adalah:

a. Menganalisis pengelolaan Anggaran Pendapatan dan Belanja Desa (APBDes) di Desa Tanjung Raja Kecamatan STM Hulu Kabupaten Deli Serdang Tahun 2017 dan 2018.

b. Menganalisis akuntabilitas pemerintah desa dalam pengelolaan Anggaran Pendapatan dan Belanja Desa (APBDes) di Desa Tanjung Raja Kecamatan STM Hulu Tahun 2017 dan 2018.

c. Menganalisis tranparansi pengelolaa Anggaran Pendapatan dan Belanja Desa di Desa Tanjung Raja Kecamatan STM Hulu Kabupaten Deli Serdang Tahun 2017 dan Tahun 2018.

\subsection{Manfaat Penelitian}

Adapun manfaat dari penelitian ini yaitu :

a. Menambah pengetahuan dan wawasan bagi penulis sendiri khususnya mengenai Anggaran Pendapatan dan Belanja Desa (APBDes).

b. Dapat menjadi bahan masukan bagi pemerintah desa khususnya di desa Tanjung Raja mengenai anggaran pendapatan dan belanja desa.

c. Sebagai bahan refrensi bagi peneliti selanjutnya untuk meneliti hal yang sama.

\section{Metodologi Penelitian}

Penelitian ini dilakukan dengan mengunakan teknik analisis data perspektif kualitatif. Analisis deskriptif kualitatif merupakan transformasi data penelitian dalam bentuk tabulasi, sehingga mudah dipahami dan diinterpresentasikan. Yang dimana cara pengumpulan data analisis deskriptif kualitatif yaitu dengan cara melakukan observasi, dokumentasi serta wawancara. Adapun wawancara tersebut dilakukan secara langung, yaitu mewawancarai beberapa orang di desa Tanjung Raja tersebut.

\section{Kesimpulan}

Berdasarkan hasil pembahasan yang ada diatas, maka dapat ditarik kesimplan sebagai berikut :

a. Pencatatan dan Pelaporan yang dilaksanakan di Desa Tanjung Raja Kecamatan STM Hulu Kaupaten Deli Serdang sudah cukup baik, karena semuanya telah menggunakan Aplikasi Sistem Keuangan Desa (SISKUDES) sesuai dengan petunjuk pelaksanaan bimbingan dan konsultassi pengelolaan keuangan desa.

b. Sistem akuntansi pelaksanaan APBDes yang di selenggarakan di Desa Tanjung Raja Kecamatan STM Hulu Kabupaten Deli Serdang telah sesuai dengan peraturan pemerintah yaitu Ankuntable, Tranparansi dan Partisipatif, hanya saja berdasarkan hasil wawancara menyatakan bahwa masyarakat masih kurang merespon/menanggapi tentang niat desa yang ingin membentuk BumDes. Hal itu dikarenakan masih tidak pahamnya masyarakat bahwa hasil dari BumDes sendiri bisa sangat bermanfaat bagi desa dan massyarakatnya. Selain itu BumDes pada Desa Tanjung Raja belum dibentuk karena masih kurangnya dana, namun pemerintah desa sebisa mungkin akan segera membentuk BumDes dalam waktu dekat ini.

c. Pertanggungjawaban APBDes sudah baik secara teknis maupun administrasi. Disini aparat pemerintah desa sudah tapat melaporkan semua bukti pertanggungjawaban dengan baik.

\section{Saran}

Berdasarkan hasil penelitian dan kesimpulan diatas tentang transparanasi dan akuntabilitasi pemerintah desa dalam pengelolaan APBDes di Desa Tanjung Raja Kecamatan STM Hulu Kabupaten Deli Serdang, maka dari itu peneliti menyarankan beberapa hal diantaranya sebagai berikut :

1. Bagi peneliti selanjutnya

a) Sebaiknya disarabkan menambah informan terutama masyarakat desa dalam pengumpulan data melalu teknik wawancara untuk dapat menilai pertanggungjawaban pemerintah desa dalam pengelolaan APBDes.

b) Kesulitan dalam keterbatasan waktu dalam melakukan wawancara dikarenakan pihak desa banyak pekerjaan, terlepas dari itu respin para 
pemerintah Desa Tanjung Raja sangat baik.

c) Sebaiknya lebih mengkoordinasikan terlebih dahulu kepada para informan mengenail waktu yang akan digunakan untuk proses wawancara.

2. Adapun saran penulis kepada Pemerintah Desa Tanjung Raja Kecamatan STM Hulu Kabupaten Deli Serdang antara lain sebagai berikut :

a) Tetap mempertahankan prinsip-prinsip dari transparansi, akuntabilitasi, partisipatif dalam pengelolaan APBDes di Desa Tanjung Raja yang telah di ipmplementasikan agar dapat menjalankan tugas dan tanggungjawab dengan baik.

b) Sebaiknya pemrintah desa melakukan Musrembang kusus untuk membahas pembentukan BumDes agar pembentukan BumDes lebih cepat terlaksana. Beri penjelasan kepada masyarakat bahwa BumDes sangat bermanfaat bagi kesejahteraan masyarakat dan Desa Tanjung Raja.

c) Pemerintah secara terus menerus merupakan fokus dari program APBDes dengan selalu mengikuti peraturan perundang-undangan terbaru, agar pemerintah desa dapat mengelola anggaran tersebut dengan baik terutama pengeluaran dana.

\section{DAFTAR PUSTAKA}

Abdussakur. (2012). Implementasi Kebijakan Anggaran Pendapatan Dan Belanja Desa (APBDes) Di Wilayah Kecamatan Batu Benawa Kabupaten Hulu Sungai Tengah Provinsi Kalimantan Selatan. Jurnal Ilmu Politik dan Pemerintahan Lokal, Volume I Edisi 2, Juli-Desember 2012, I, 107-135.

Badan Penerbit Universitas Islam Sumatera Utara Medan. (2017). Buku Panduan Cara Penulisan Makalah, Proposal, Skripsi dan Artikel Ilmiah", Medan

Balderton. (2011). Efektivitas Pemerintah Desa Dalam Mengelola Dana Desa Di Desa Tonsewer Kecamatan Tompaso Barat Kabupaten Minahasa. Jurnal Jurusan Ilmu Pemerintahan, Volume 1, No 1 2018, 1-9.

Bawias, R., Masje, P., \& Arie, R. (2015). pengelolaan anggaran pendapatan dan belanja desa dalam menunjang pembangunan di desa butunuris kecamatan salibabu kabupaten kepulauan talaud. Jurnal Administrasi Publik, Vol 4, No 32 (2015), 4, 1-135. berdesa. (2018, Desember 19). Definisi Desa Menurut Berbagai Ahli. Retrieved from berdesa.com:

https://www.berdesa.com/definisi-desamenurut-berbagai-ahli.

Ceper, G. (2012, Juni 11). Tinjauan Tentang Geografi Perdesaan. Retrieved from,http://agussunthe.blogspot.com/:http:// agussunthe.blogspot.com/2012/06/tinjauantentang-geografi-perdesaan.html.

Dyah Purwitasari, Muhtar. (2013) "Analisis

Perbandingan dan Analisis Sumber Serta Penggunaan Dana Pada APBDes Slemanan". Jurnal Akuntansi

Endang Kusmila. (2019) "Analisis Sistem Pelaksanaan Anggaran Pendapatan Dan Belanja Desa (APBDes). Jurnal Riset Ekonomi, Manajemen, Bisnis Akuntansi

Faradhiba, L., \& Diana, N. (2018). Akuntabilitas Pemerintahan Desa Dalam Pengelolaananggaran Pendapatan Dan Belanja Desa (APBDES). E-JRA Vol. 07 No. 07 Agustus 2018, 07, 14-28.

Hamalik. (2014). Wida, P. (4). Pengelolaan Anggaran Pendapatan Dan Belanja Desa Oleh Pemerintah Desa Di Desa Parakanmanggu Kecamatan Parigi Kabupaten Pangandaran. Dinamika Vol 4, No 1 (2017), 4, 1-8.

Hasanah, S. (2017, January 12). Syarat dan Ketentuan Pembentukan Desa. Retrieved from

www.hukumonline.com:https://www.hukum online.com/

klinik/detail/ulasan/lt584c27a3a475e/syaratdan-ketentuan-pembentukan-suatu-

desa/Indonesia.

Iqsan. (2016). Transparansi Pemerintah Desa Dalam Penyusunan Anggaran Pendapatan Dan Belanja Desa (APBDES). E-Joournal Ilmu Pemerintahan, 04, 1-11.

Lestari, Y. (2018). Akuntabilitas Pemerintah Desa Dalam Pengelolaan Anggaran Pendapatan Dan Belanja Desa (APBDES). Jurnal Skripsi, 1-11. Mengenal Anggaran Pendapatan dan Belanja Desa (APBDes). (2015, November 13). Retrieved from berdesa:

Moekijat. (2014). Wida, P. (4). Pengelolaan Anggaran Pendapatan Dan Belanja Desa Oleh Pemerintah Desa Di Desa 
Parakanmanggu Kecamatan Parigi Kabupaten Pangandaran. Dinamika Vol 4, No 1 (2017), 4, 1-8.

Pemerintah Indonesia. 2006. Undang-undang No. 6 Tahun 2014 Yang Mengatur Tentang Desa. Lembaran Negara RI Tahun 2014, No 5495. Jakarta : Sekretariat Negara

Peraturan Menteri Dalam Negeri. 2018. Peraturan Kemenenterian Dalam Negeri Tentang Pengelolaan Keuangan Desa. Peraturan Kementrian Dalam Negeri Tahun 2018, No 611. Jakarta

Prajudi. (2014). Wida, P. (4). Pengelolaan Anggaran Pendapatan Dan Belanja Desa Oleh Pemerintah Desa Di Desa Parakanmanggu Kecamatan Parigi Kabupaten Pangandaran. Dinamika Vol 4, No 1 (2017), 4, 1-8.

Puspawardani, W. (2017, Februari 03). Pengelolaan Anggaran Pendapatan Dan Belanja Desa Oleh Pemerintah Desa. EJurnal Ilmiah Ilmu Administrasi Negara Vol. 4 No. 1 2017, 4, 1-8.

Setiawan, E. (2012). Kamus Besar Bahasa Indonesia (KBBI). Retrieved from https://kbbi.web.id/desa

Sriartha. 2014. Tinjauan Tentang Geografis Perdesaan.

http://agussunthe.blogspot.com/2012/06/tinj auan-tentang-geografi-

perdesaan.html\#: :text=Dalam\%20konteks \%20pembangunan $\% 20 \mathrm{desa} \% 2 \mathrm{C} \% 20$ pemeri ntah,Sriartha\%2C\%202004\%3B\%2013).

Sugiyono, (2010). Metodelogi Penelitian Kuantotatif Kualitatif dan R\&D. Catatan ke-10. Jakarta: Selemba Empat.

Sugiyono, (2014). Metode Penelitian

Kuantitatif Kualitatif dan R\&D. Alfabeta. Bandung

Suhairi. (2016). Analisis Pendapatan Desa Terhadap Belanja Desa. Jurnal Skripasi, 19. Retrieved from

Syarifudin dan Na'a. 2010. Analisis Transparansi Dalam Pengelolaan Anggaran Pendapatan dan Belanja Desa di Desa Teluk Beringin Kecamatan Gunung Toar Kabupaten Kuantan Singingi. Jurnal skripsi 2019.

Wida, P. (4). Pengelolaan Anggaran Pendapatan Dan Belanja Desa Oleh Pemerintah Desa Di Desa Parakanmanggu Kecamatan Parigi Kabupaten Pangandaran. Dinamika Vol 4, No 1 (2017), 4, 1-8. Retrieved from 